Chapter 2

\title{
Systematic Techniques for the Recognition of Anopheles Species Complexes
}

\author{
Wej Choochote and Atiporn Saeung \\ Additional information is available at the end of the chapter \\ http://dx.doi.org/10.5772/54853
}

\section{Introduction}

Throughout the world, 528 species of Anopheles mosquitoes have been discovered, and approximately 80 of them play an important role as vectors of malaria, filarial nematode and encephalitis virus. Among these, at least 20 taxa represent species complexes, which comprise about 115 sibling species members. The existence of species complexes in Anopheles vectors leads to difficulty in precisely identifying sibling species (isomorphic species) and/or subspecies (morphologically/cytologically polymorphic races) members that possess identical morphology or minimal morphological distinction. In addition, those members may differ in biological characteristics (e.g., microhabitats, resting and biting behavior, sensitivity or resistance to insecticides, susceptible or refractory to malaria parasites, etc.), which can be used to determine their potential for transmitting disease agents. Incorrect identification of individual members in Anopheles species complexes may result in failure to distinguish between a vector and non-vector, and lead to complications and/or unsuccessful vector control [1-5].

So far, at least 1 and 2 traditional techniques have been used widely for the recognition of sibling species and/or subspecies members at post- and pre-mating barriers. For post-mating barriers; the hybridization or crossing experiment, using the artificial mating technique to determine hybrid non-viability, sterility or breakdown, is still a useful tool for recognizing Anopheles species complexes. Detailed genetic incompatibility, including lack of insemination, embryonation, hatchability, larval survival, pupation, emergence, adult sex distortion, abnormal reproductive system and complete or incomplete (some cases only at the inversion heterozygote regions) asynaptic salivary gland polytene chromosomes are useful criteria for elucidating sibling species and subspecies status. However, a point worth noting is that an isofemale line (isoline) colony established from the combinative characters of morphological and/ or cytological markers has to be considered seriously. A laboratory raised colony established 
from a naturally mixed population should be omitted, since it may be a mixture of cryptic species [6-10]. In addition, many Anopheles species do not reproduce in captivity. As for premating barriers; examination of the polytene chromosomes in wild-caught adult females, and/ or progenies of iso-female lines, provides clear evidence that different specific mate recognition systems (SMRS) exist. The total absence or significantly deficient number of heterozygotes for an inversion in a sympatric population entirely indicates the presence of reproductive isolation within a taxon [10-12]. Nonetheless, at least 4 problems have been raised regarding this matter, i.e., (1) a skilled person is needed to prepare a perfect chromosome and make an identification, (2) homosequential banding species cannot be employed, e.g., An. maculipennis complex [13] and An. barbirostris complex [14-17], (3) a relatively large amount of sample materials are required to perform the Hardy-Weinberg equilibrium, which cannot be applied to small numbers of rare species specimens that are caught during specific seasons, and (4) it cannot be performed in allopatric anopheline populations. Electrophoretic variations at enzyme loci are not only useful for identification of sibling species, but also for the correct identification of morphologically cryptic Anopheles species. Variations at a locus thus enable detection of reproductive isolation within populations, resulting from positive assortative (preferential) mating [10-11, 18]. Nevertheless, at least 2 problems have been raised regarding this technique, i.e., (1) specimens must be fresh or frozen until analysis, and (2) its use must be similar to that of the polytene chromosome, as it requires a relatively large amount of sample materials to perform the Hardy-Weinberg equilibrium and cannot be performed in allopatric anopheline populations, as previously described.

Regarding the modernized technique; molecular investigation of some specific genomic markers, e.g., ribosomal DNA (ITS2, D2, D3, IGS) and mitochondrial DNA (COI, COII, Cyt b, ND5), has been used extensively as a tool to characterize and/or diagnose cryptic members in the intra-taxa of Anopheles mosquitoes, and the advantage of this PCR-based technique is that few nanograms of DNA are required from preserved specimens [19]. Nonetheless, controversy arose when only comparative DNA sequence analyses of some specific genomic regions were used as first hand criteria to differentiate between the status of specific species, sibling species and subspecies within the taxon Anopheles. For example, based on a comparison of the D3 domain of 28S (28S-D3), An. fluviatilis S has been considered as synonymous to the An. minimus species $C$ [20-22]. However, subsequent investigation of the conspecificity of these two species, based on ITS2 and D2-D3 domains of $28 \mathrm{~S}$ rDNA regions, suggests that An. fluviatilis $\mathrm{S}$ and An. minimus $\mathrm{C}$, do not deserve to be synonymous [23]. Similar results were also obtained in the determining on specific species status between An. lesteri and An. paraliae [unpublished data]. The comparative DNA sequence analyses between An. lesteri strain from Korea and An. paraliae strain from Thailand revealed low pairwise genetic distance for COI (0.007-0.017) and COII (0.008-0.011) regions with 4-9 and 5-7 base substitutions, respectively, whereas a considerable genetic distance $(0.040)$ was obtained in ITS2 region with 16 base substitutions. Supportively, the phylogenetic trees demonstrated that these two species were separated from each other with a 74-100\% bootstrap value for 3 regions. It was interesting to note that An. lesteri and An. paraliae were distinguished appreciably by DNA sequence data, however, were confirmed to be genetically compatible by the crossing experiments. Remarkably, prior to reaching a definite conclusion of specific species, sibling species and subspecies 
status within the taxon Anopheles, crossing experiments need to be carried out intensively using iso-female lines established from sympatric and/or allopatric populations, which relate to morphological variants, cytogenetic forms and/or comparative DNA sequence analyses of some specific regions.

\section{Formation of robust systematic procedures}

In light of the advantages and disadvantages of the techniques mentioned above, 3 techniques, i.e., the crossing experiment, molecular investigation and cytogenetic markers (characteristics of metaphase karyotypes) were selected, and they formed the robust systematic procedures for the recognition of Anopheles species complexes [24] (Figure 1).

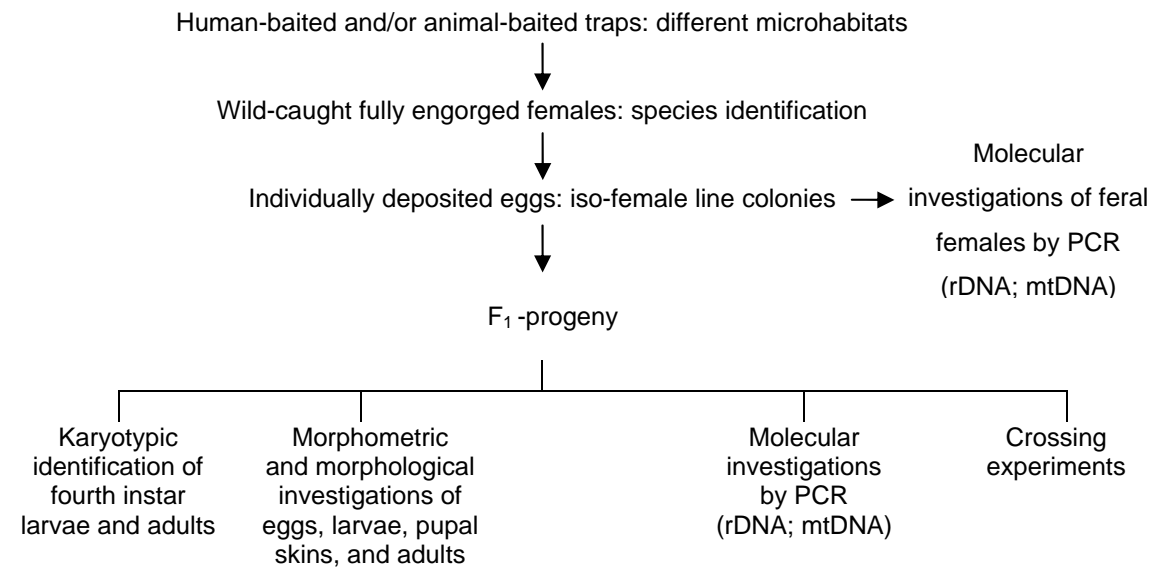

Figure 1. Summarized flow chart for robust systematic procedures

By following the flow chart: (1) try to collect anopheline mosquitoes that are distinct in their behavior (e.g., biting humans or animals with relation to different microhabitats and/or locations), (2) try to record morphological variation(s) as far as possible during the species identification process of wild-caught females, (3) establish an iso-female line colony by allowing gravid females to lay eggs individually, (4) conduct molecular investigation of laidegg feral females to obtained a robust DNA marker, with this step usually taking about 1 week. Since development of the $\mathrm{F}_{1}$-progeny usually takes about 2 weeks from first instar larvae to adults, the metaphase karyotype investigation of fourth instar larvae, newly emerged adult females and males is performed in order to (5) obtain a cytogenetic marker (karyotypic form), (6) if molecular investigation fails in the step of laid-egg feral female it will be performed in $\mathrm{F}_{1}$-progeny, (7) carry out morphometric and morphological investigations of eggs, larvae, pupal skins and adults to confirm precise species identification, and (8) perform the important 
step of crossing experiments among iso-female line colonies by using a karyotypic marker (or form) related to a DNA marker (large sequence divergence or very low intraspecific sequence variation) of each iso-female line colony.

Regarding techniques necessary for success in operating robust systematic procedure: 3 important techniques were developed by the authors, and they have been proven as efficient and necessary for the robust systematic recognition of sibling species and/or subspecies members within the taxon Anopheles species complex. They are: (1) the establishment of a healthy iso-female line colony that is the backbone of population-genetic study on Anopheles vectors, since it provides healthy larval and adult progenies for preparation of attractive metaphase and salivary gland polytene chromosomes, and potent adults for crossing experiments. The inability to establish a healthy iso-female line colony that can be colonized for many consecutive generations is the principle cause of failure in a population-genetic study of Anopheles vectors, (2) the technique for metaphase chromosome preparations in adult females and males by intrathoracic inoculation [25] and that for fourth instar larval brains [14] using extracted solution derived from dried seeds and rhizomes of a decoration plant (Gloriosa superba L.), instead of synthetic colchicine solution, and (3) modified technique for salivary gland polytene chromosome preparations in fourth instar larvae [26]. Detailed and important procedures regarding the 3 techniques are as follows:

\section{Techniques for establishment of a healthy iso-female line colony of difficult-to-rear anophelines}

An iso-female line colony of An. campestris-like Form E, Thai strain [14] was established from 1 wild-caught fully engorged adult female collected from a human-baited trap reared successfully under laboratory conditions for 98 consecutive generations and used as a role model for other fresh-water breeding anopheline species.

\section{Procedures}

\subsection{Transportation of wild-caught anophelines}

Wild-caught fully engorged adult females collected from human- and/or animal-baited traps in the field were kept in a plastic cup $(8.5 \mathrm{~cm}$ in diameter and $11 \mathrm{~cm}$ in depth, lined inside with filter paper), with a pad of cotton wool soaked with $10 \%$ sucrose solution placed on top of the covering screen. It was covered with a translucent plastic bag in order to keep humid conditions in the cup and delay rapid drying of the soaked cotton wool (Figure 2a). It was stored in a humid chamber using a picnic foam-box $(18 \times 26 \times 39 \mathrm{~cm})$ to maintain humidity and temperature (Figure $2 \mathrm{~b}$ ). Then it was transported to the insectarium for colonization and biological studies. All of the experiments were performed in the insectarium at $27 \pm 2{ }^{\circ} \mathrm{C}, 70-80 \%$ relative humidity, and illumination from a combination of natural daylight from a glasswindow and fluorescent lighting was provided for approximately 12 hours a day. 

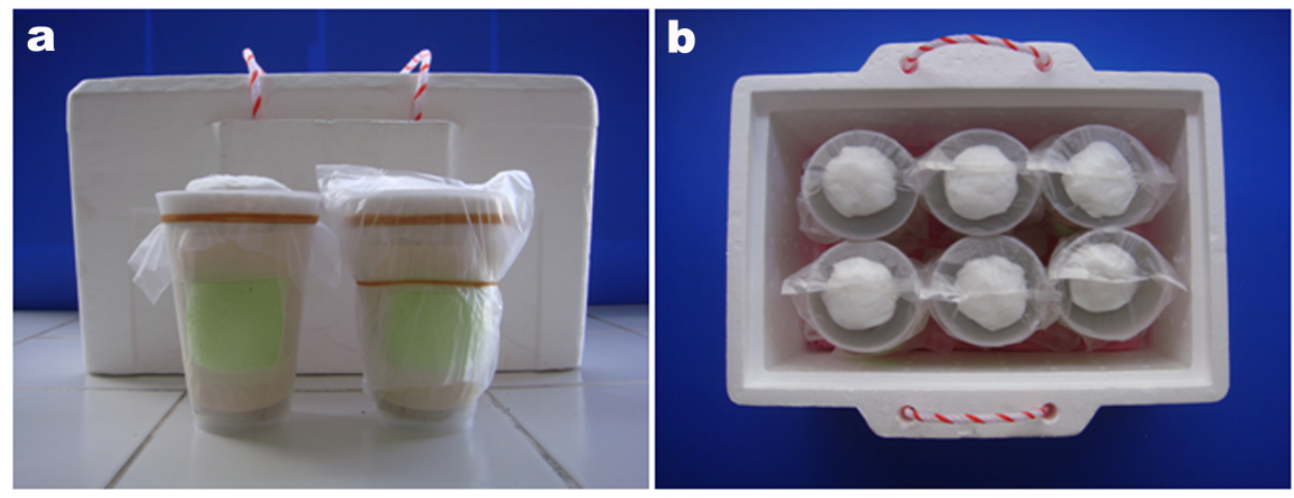

Figure 2. (a) A screen-topped plastic cup with a pad of soaked cotton wool placed on top of the covering screen (left), covered with a translucent plastic bag (right), and a humid chamber derived from a picnic foam-box (background). (b) Top view of the humid chamber showing 6 plastic cups placed on a wet towel lined the bottom (pink colour) and 10-15 ice cubes

\subsection{Egg laying}

After the engorged adult female was maintained for 4-5 days and/or until gravid in the insectarium, it was placed in a screen-topped oviposition plastic-cup $(6 \mathrm{~cm}$ in diameter and 7 $\mathrm{cm}$ in depth) containing $25 \mathrm{ml}$ of natural water (brought from a basin that was used for tapwater production). Wet filter paper lined the inside of the screen-topped was covered with a black plastic sheet (Figure 3a-c). The eggs attached to the moist side of the filter paper and/or floating on the water surface were rinsed and transferred to white plastic tray $(25 \times 36 \times 6 \mathrm{~cm})$ containing 1,500 $\mathrm{ml}$ rearing water (equal part of natural water and distilled water) with wet filter paper lining the inside. During the embryonation period, the eggs were exposed to a 40watt light instead of sunlight, for warming the eggs until hatching (Figure 3d).

\subsection{Rearing of larvae, pupae and adults}

After egg hatching, first instar larvae were transferred daily from an ovipot to a white plastic tray $(25 \times 36 \times 6 \mathrm{~cm})$ containing 2,000 ml rearing water and approximately 15 stems of garden grass (Axonopus compressus), and 80 first instar larvae were reared in each tray. The rearing tray was covered with a transparent plastic sheet for reducing the need to change and/or refill the tray with rearing water during the larval development process (Figure 4a-b). An extra and/or a standard formula of fish food consisting approximately of protein $47.5 \%$, oil $6.5 \%$, fibre $2.0 \%$, ash $10.5 \%$, moister $6.0 \%$ and additives of vitamins A $(29,770 \mathrm{IU} / \mathrm{kg}), \mathrm{D} 3$ (1,860 IU/ $\mathrm{kg}), \mathrm{E}(200 \mathrm{mg} / \mathrm{kg}), \mathrm{L}$-ascorbyl-2-polyphosphate $(138 \mathrm{mg} / \mathrm{kg})$, lecithin, l-lysine monochlorhydrate, and citric acid was used as larval nutrient. Fine fish food was placed in a vial covered with a nylon screen $\left(34 \times 43\right.$ threads per $\left.\mathrm{cm}^{2}\right)$ and sprinkled on the water until the food particles stopped spreading across the water's surface. First and second instar larvae were fed twice daily, and this schedule was increased to 3-5 times daily after most of the larvae reached third and fourth instars, respectively. Before each feeding, floating clumps of excess food were 


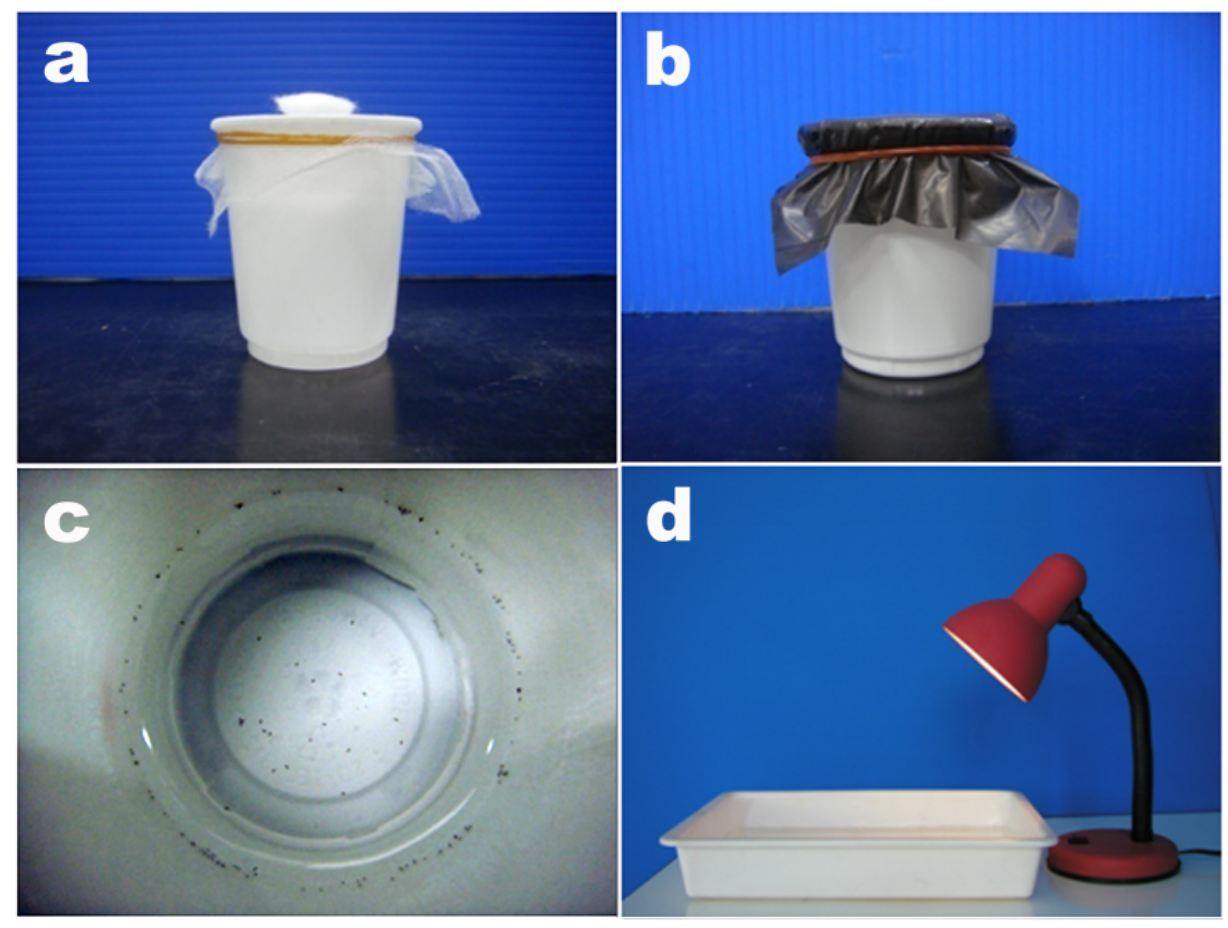

Figure 3. (a) A screen-topped oviposition plastic-cup, (b) covered with a black plastic sheet, and (c) top view of the plastic cup showing egg-batch after 12-hours-oviposition of a gravid adult female. (d) Eggs placed in a white plastic tray and exposed to a 40-watt light

removed by dragging a sheet of typing-paper across the water's surface. Any larvae trapped on the paper during the cleaning process were dislodged by rinsing the paper in a tray of rearing water and returning it to the rearing tray. After pupation, approximately 100 pupae placed in a plastic cup $(14.5 \mathrm{~cm}$ in diameter and $6 \mathrm{~cm}$ in depth) containing $150 \mathrm{ml}$ of distilled water were kept in a $30 \times 30 \times 30 \mathrm{~cm}$ cage, and the emerged adults were provided with both $10 \%$ sucrose solution and $5 \%$ multivitamin syrup solution (consisting approximately of vitamins A: 2,000 I.U., D: 200 I.U., E: 1.50 I.U., B1: 0.70 mg, B2: 0.85 mg, B6: 0.35 mg and C: 17.50 mg, nicotinamide: $9.00 \mathrm{mg}$, orange juice: $0.50 \mathrm{~g}$ and cod liver: $0.10 \mathrm{~g}$ per $100 \mathrm{ml}$ solution) saturated in cotton wool coiled around a small piece of wood and placed in a small bottle. Increased humidity to promote adult survival was provided by covering the cage with a wet towel overlaid with a black plastic sheet (Figure 4c). One-day-old males were removed daily from the cage and kept in a screen-topped plastic cup (lined inside with filter paper), where they were provided with a $5 \%$ multivitamin syrup solution through a pad of soaked cotton wool, which was placed on top of the screen and changed daily. In order to keep humid conditions in the cup and delay rapid drying of the cotton wool soaked in 5\% multivitamin syrup solution, the screen-top was covered with a translucent plastic bag (Figure $4 \mathrm{~d}$ ). 


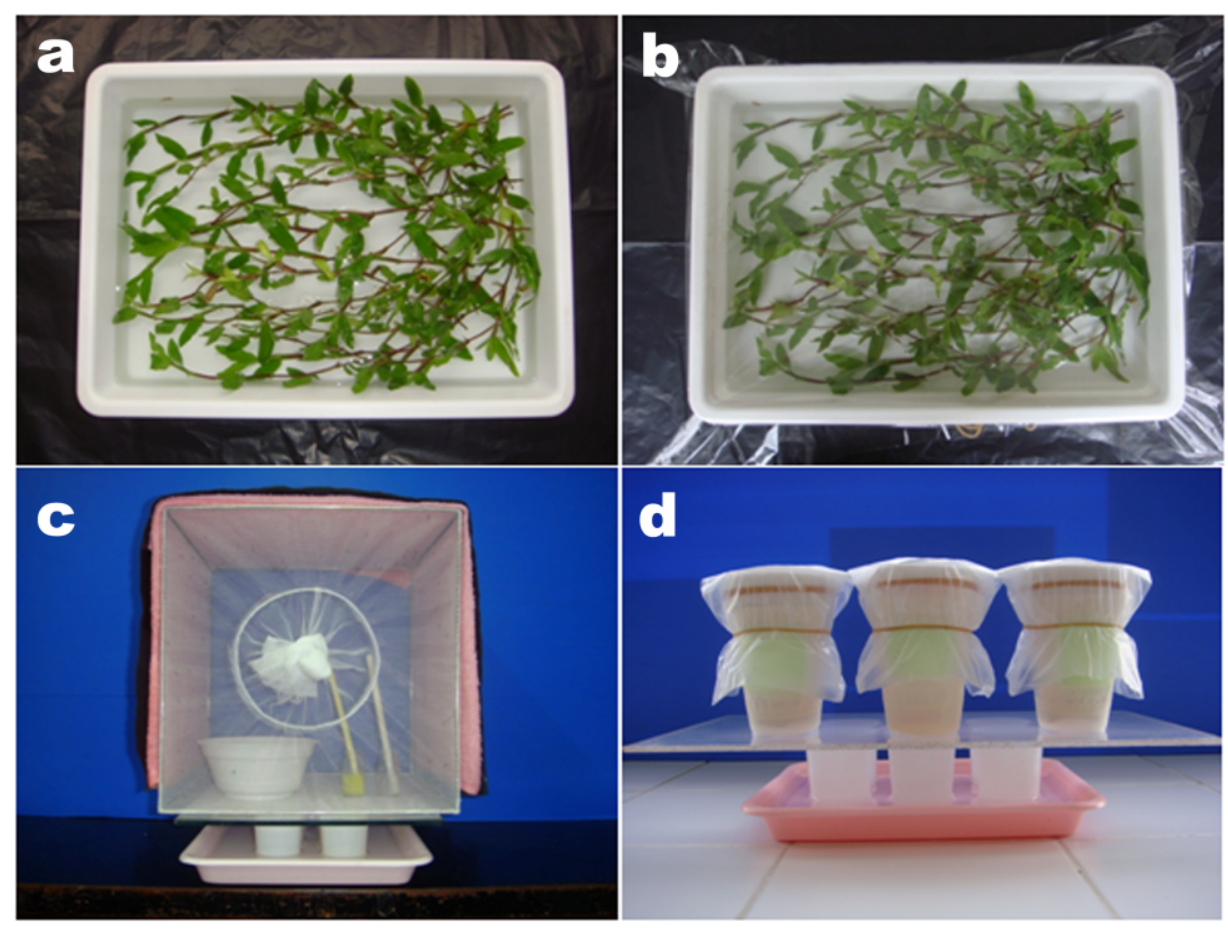

Figure 4. (a) Top view of a white plastic tray placed with 15 stems of garden grass, and (b) covered with a transparent plastic sheet. (c) Adult rearing cage partially covered with a wet towel (pink colour) and a black plastic-sheet with plastic container for holding pupae, and two bottles with cotton wicks, one containing $10 \%$ sucrose solution and another $5 \%$ multivitamin syrup solution. (d) Adult males being kept in a screen-topped plastic cup (lined inside with filter paper) with a pad of cotton wool soaked in $5 \%$ multivitamin syrup solution and the top covered with a translucent plastic bag to maintain humidity.

\subsection{Suitable blood-feeding condition}

Comparative direct feeding ability on white rat in a $30 \times 30 \times 30 \mathrm{~cm}$ cage, and artificial feeding ability on human heparinized-blood (obtained from human volunteers whom sign the consent form) in a plastic cup ( $8.5 \mathrm{~cm}$ in diameter and $11 \mathrm{~cm}$ in depth, lined inside with filter paper) (Figure 5), of female An. campestris-like Form E at different ages ranging from 1 to 10 days, demonstrated that in the cage, adult females aged of 3, 4, 5 and 6 days were successful in feeding on the blood of white rats, with feeding rates of $30 \%, 39 \%, 62 \%$ and $43 \%$, respectively. Interestingly, the adult females aged 3, 4, 5, and 6 days succeeded in artificial feeding on human heparinized-blood in the plastic cup at higher rates than direct feeding on white rat in the cage in all experiments by yielding feeding rates of $62 \%, 68 \%, 78 \%$ and $61 \%$, respectively. Nevertheless, the engorged females that derived from 2 feeding methods were used satisfactorily for the maintenance of an iso-female line laboratory-raised colony of An. campestris-like Form E. One difficulty and/or failure in rearing mosquitoes in the laboratory was the subsequent 
generation's refusal to feed on blood, particularly from small laboratory animals such as guinea pig, white rat, golden hamster, etc. This leads to direct feeding from human volunteers, especially at the beginning of the first to fifth generations of the colony. However, to solve this problem, forced artificial feeding on human heparinized-blood by An. campestris-like Form E was successful in this study and has been used routinely up to this time. Nonetheless, a point to be kept in mind is that only the healthy progenies of laboratory-raised colonies could be used successfully. Additionally, the use of direct blood feeding of subsequent mosquito progenies from human volunteers is a potentially dangerous method and should be given up entirely, since at least 4 reports have declared that An. peditaeniatus [27], An. subpictus [28-29] and An. barbirostris [30] have been incriminated as secondary vectors of Japanese encephalitis virus, which is possibly transmitted vertically.

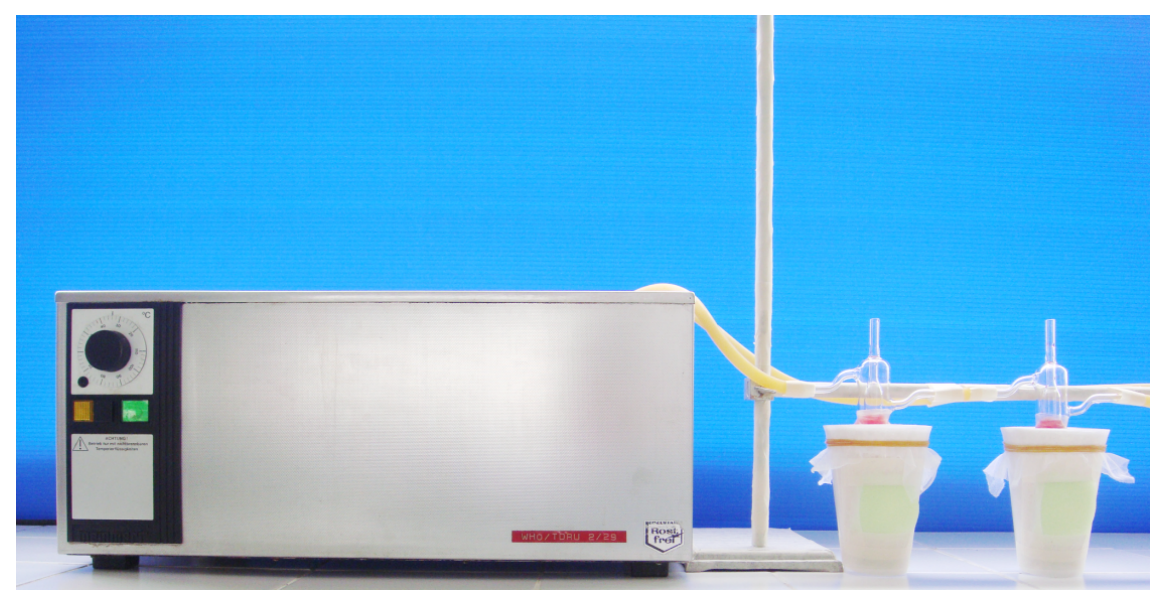

Figure 5. Artificial feeding system. A warm water-bath at $40^{\circ} \mathrm{C}$, with a water pump placed inside, is connected to glass inlet and outlet feeding-chambers by rubber tubes. Thin paraffin-membrane covers the bottom tip of the feeding chambers, which are filled with human heparinized-blood, and the bottom tip is in close contact with 50 fasted adult female An. campestris-like Form E that are inside a screen-topped paper cup.

\subsection{Ability of free mating in a $30 \mathrm{~cm}$ cubed cage and male ability to mate artificially}

One of the difficulties in the colonization of anopheline mosquitoes in the laboratory might be due to adults not being capable of copulation in a small and/or standard cage $(30 \times 30 \times 30 \mathrm{~cm})$. Thus, in order to determine the adaptive stenogamy of An. campestris-like Form E, the newly emerged females and males co-habitated at a ratio of 200/300, in a $30 \times 30 \times 30 \mathrm{~cm}$ cage for one week [31-32]. The results indicated that An. campestris-like Form E failed to mate freely in the cage at a $0 \%$ insemination rate (from experiments repeated 3 times), indicating strong eurygamy. Thus, the artificial mating methods as described by [33-34] were used. The best age for artificial mating in male An. campestris-like Form E was 5-days-old (100\% mating rate, $86.67 \%$ insemination rate). Nonetheless, males aged 4 and 8 days old could be used satisfactorily (93.33-100\% mating rates, $80-82.14 \%$ insemination rates) (Table 1 ). 


\begin{tabular}{ccc}
\hline Day after emergence* & No. successfully mated females (\%) & No. insemination (\%) \\
\hline 1 & $11(36.67)$ & $18(78.26)$ \\
\hline 2 & $23(76.67)$ & $18(78.26)$ \\
\hline 3 & $23(76.67)$ & $24(80.00)$ \\
\hline 4 & $30(100)$ & $26(86.67)$ \\
\hline 5 & $30(100)$ & $23(82.14)$ \\
\hline 6 & $28(93.33)$ & $24(85.71)$ \\
\hline 7 & $28(93.33)$ & $23(82.14)$ \\
\hline 9 & $28(96.63)$ & $16(61.54)$ \\
\hline
\end{tabular}

*Thirty males for each experiment.

Table 1. Artificial mating ability of An. campestris-like Form E males

\subsection{Searching for a suitable oviposition-condition}

Many anopheline colonies have been reported to adapt easily to oviposit eggs in the cage on various types of simple ovipots, e.g., petridish, crystallizing dish, terra-cotta bowl, white plastic cup, black cup, etc. [35-39]. In the case of using 20 gravid adult females of An. campestris-like Form E put in a $30 \times 30 \times 30 \mathrm{~cm}$ cage for 12 hours (starting from 18.00-06.00 hours), the results revealed that $0,0,279,0$ and 0 eggs per an oviposited-plastic cup $(9 \mathrm{~cm}$ in diameter and $10.5 \mathrm{~cm}$ in depth, containing $80 \mathrm{ml}$ of natural water) were found in experiments $1,2,3,4$ and 5 , respectively; whereas the forced laying of eggs by placing 20 gravid adult females in an oviposited-plastic cup (details mentioned above in paragraph 2 "Egg laying") in the same size and conditions as used in the cage, a massive number of eggs, i.e., 1,273, 1,318, 1,705, 2,180 and 1,501 eggs per cup, were recovered for experiments 1, 2, 3, 4 and 5, respectively (Figure 6). The high yield of eggs recovered from the latter experiment appears to result in the fact that the close-system of an oviposited-plastic cup provided significantly higher relative humidity than a cage or open-system. The air-rich water molecules in high relative humidity are the important attractants to gravid female alfactometer, which indicates suitable or acceptable oviposition sites [40]. Thus, in oviposition of An. campestris-like Form E and other anopheline species in our laboratory, this method has been used routinely up until now. 


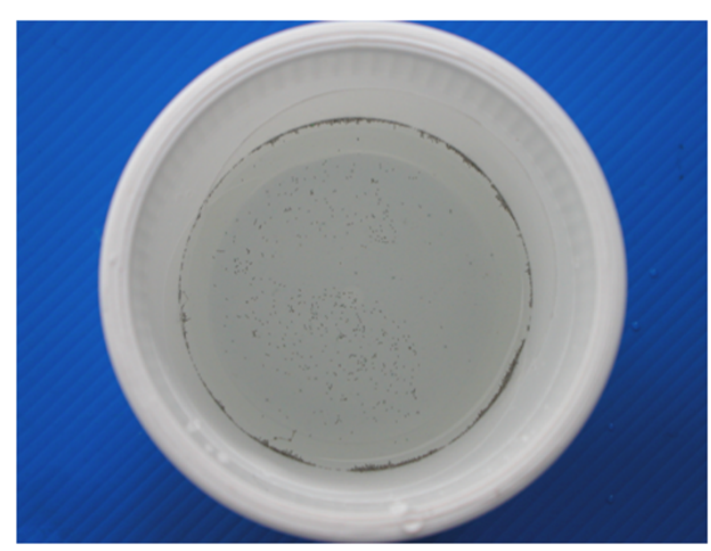

Figure 6. Top view of ovipot derived from a plastic cup showing massive egg-batches after 12-hours-oviposition of the 20 gravid adult females

\subsection{Other important factors}

Throughout the larval rearing period, the number of larvae, rearing conditions in the tray, and food were the most important factors, not only for routine rearing, but also special rearing in order to obtain a high yield of metaphase and polytene chromosomes, which were necessary for population-genetic study of anophelines. Stressful rearing-conditions, e.g., the overcrowding of larvae in a rearing tray (in this study, 80 larvae per $25 \times 36 \times 6 \mathrm{~cm}$ tray was an appropriate number for An. campestris-like Form E), and the use of inappropriate water medium and food would lead to a rapid drop in and/or loss of a colony. Also, this would result in low larval and pupal survival rates, adult $\mathrm{F}_{1}$-progenies refusing to take blood meal, difficulty in artificial mating of adult females and males and/or failure to inseminate sperm into mated-female spermathecae, short life span of adult females and males, mated gravid adult females laying fewer numbers of eggs and/or failure to lay eggs, and low egg-hatchability. Thus, any rearing system, which is an important first step that leads to obtaining healthy larvae, would be a promising method for successfully establishing a colony, particularly an iso-female line colony, which is more difficult and complicated to establish than a mixed colony. As mentioned previously, food was one of the most important factors for obtaining healthy larvae, thus, several kinds of larval food were tested for use and comparison, e.g., mouse pellets, cat and dog biscuits and various formulas of fish food. The results indicated that the standard formula of fish food as mentioned in paragraph 3 ("Rearing of larvae, pupae and adults"), proved to be an excellent larval food for An. campestris-like Form E. It is expected that this fish food formula was also ideal for other anopheline species with rearing difficulties. The use of equal part of natural water and distilled water as the larval rearing medium also proved to be promising. Trials using boiled tap-water, filtered tap-water, polarized water and deionized water yielded unsatisfactory outcomes by providing low larval survival, particularly through subsequent progenies. The addition of garden grass to the larval rearing tray, as stated by [31], resulted in high larval survival for An. campestris-like Form E. Using few stems of garden grass, 
or withdrawing it, would lead to low larval survival and/or weak larvae for rearing subsequent generations. Using slightly more or less than 15 stems of garden grass, depending upon the size of the stems, and size and number of leaves, proved to improve conditions to a suitable level for larval rearing, since the grass provided a resting place for larvae, rendered shade as in natural breeding sites (rice paddy, ponds and swamps associated with water plants) [41-42], and aerated the medium. Its roots were also very important for maintaining clear and clean rearing medium by using larval waste products and unconsumed food as fertilizer, which determined the obvious active growth of grass in the rearing tray. Finally, we hope that the detailed information concerning rearing aspects of An. campestris-like Form $\mathrm{E}$ will prove to be important for the establishment of other anopheline species that have been previously difficult to rear.

Notes: By following the systematic rearing procedures as detail-mentioned above, at least 23 Anopheles species were successful reared in our insectarium, i.e., subgenus Anopheles [An. argyropus $\left(\mathrm{F}_{23}\right)$, An. barbirostris species $\mathrm{A} 1\left(\mathrm{~F}_{86}\right)$, An. belenrae $\left(\mathrm{F}_{26}\right)$, An. campestris-like Form $\mathrm{E}\left(\mathrm{F}_{98}\right)$, An. crawfordi $\left(\mathrm{F}_{23}\right)$, An. lesteri $\left(\mathrm{F}_{60}\right)$, An. nigerrimus $\left(\mathrm{F}_{23}\right)$, An. nitidus $\left(\mathrm{F}_{28}\right)$, An. paraliae $\left(\mathrm{F}_{24}\right)$, An. peditaeniatus $\left(\mathrm{F}_{23}\right)$, An. pullus $\left(\mathrm{F}_{24}\right)$, An. pursati $\left(\mathrm{F}_{24}\right)$ and An. sinensis $\left.\left(\mathrm{F}_{28}\right)\right]$; and Cellia $[$ An. harrisoni $\left(\mathrm{F}_{51}\right)$, An. jamesii $\left(\mathrm{F}_{10}\right)$, An. jeyporiensis $\left(\mathrm{F}_{5}\right)$, An. karwari $\left(\mathrm{F}_{13}\right)$, An. kochi $\left(\mathrm{F}_{25}\right)$, An. nivipes $\left(\mathrm{F}_{12}\right)$, An. pampanai $\left(\mathrm{F}_{11}\right)$, An. philippinensis $\left(\mathrm{F}_{12}\right)$, An. splendidus $\left(\mathrm{F}_{10}\right)$ and An. tessellatus $\left.\left(\mathrm{F}_{27}\right)\right]$.

\section{Techniques for metaphase and polytene chromosome preparations}

\subsection{Rearing condition of mosquitoes for chromosome preparations}

The methods for rearing conditions were generally routine as mentioned in paragraph 3 , except, 10 first instar larvae per tray were used to obtain a high yield of metaphase chromosomes from larval brains, ovaries and testes, and polytene chromosomes from larval salivary glands. Comparative outcome rates of metaphase chromosomes from larval brains and polytene chromosomes from larval salivary glands between routine (80 larvae) and special (10 larvae) rearing revealed as follows: (1) metaphase chromosomes: experiment 1 [10 larvae $(87.50 \%)$ vs. 80 larvae (33.33\%)], 2 [10 larvae (75.00\%) vs. 80 larvae (30.00\%)] and 3 [10 larvae (77.78\%) vs. 80 larvae (30.00\%)]; and (2) salivary gland polytene chromosomes: experiment 1 [10 larvae ( $80.00 \%)$ vs. 80 larvae $(50.00 \%)$ ], 2 [10 larvae $(66.67 \%)$ vs. 80 larvae $(50.00 \%)$ ] and 3 [10 larvae $(100.00 \%)$ vs. 80 larvae $(66.67 \%)]$. Thus, a special rearing with 10 larvae was used routinely for chromosome preparation.

\subsection{Preparation of metaphase chromosomes from adult females and males and fourth instar larvae}

\subsubsection{Preparation of $0.5 \%$ and $1 \%$ solutions of dried Gloriosa superba seed and rhizome powders}

Summarized flow chart for normal saline-extracted Gl. superba seed and rhizome powders, as follows: 


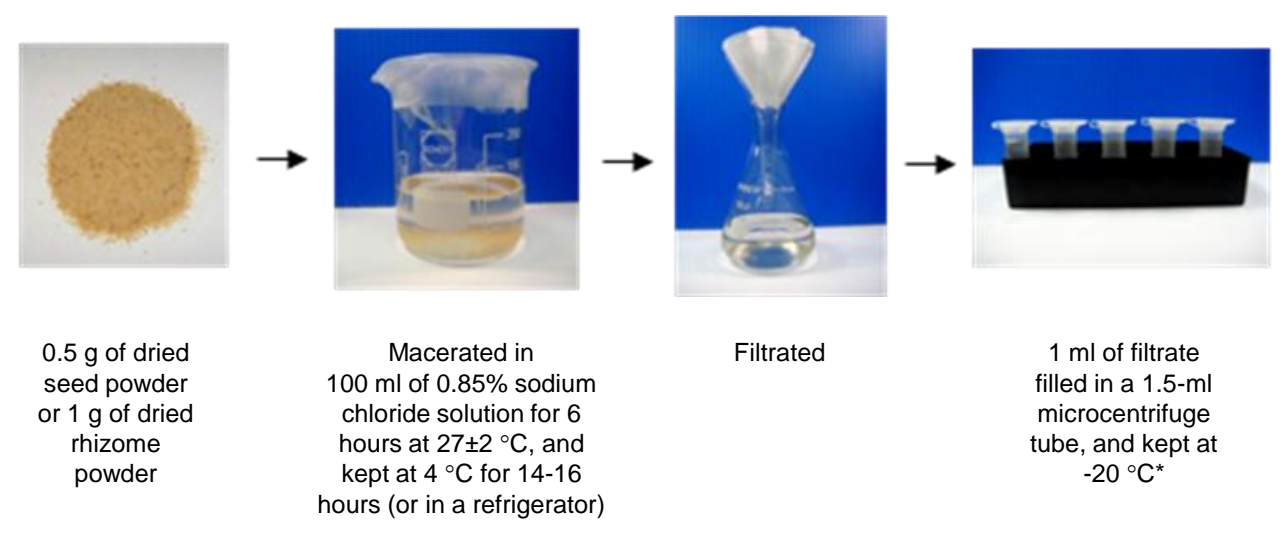

*By keeping at this condition, the colchicine-like activity in the filtrate stays stable for at least 2 years.

Notes: colchicine solution has been used widely at a concentration of $0.05-1 \%$ for metaphase chromosome preparation in the cytogenetic study of eukaryotic organisms, e.g., protozoans [43], helminthes [44-45], snails [46], insects [8, 47-50], and plants [51-52]. Spindle formation or microtubule polymerization inhibits arresting mitosis at the metaphase [53-54]. The alkaloid colchicine was isolated from a plant named autumn crocus or meadow saffron (Colchicum autumnale L., Family Liliaceae) in 1820 by Pelletier and Caventou [53]. At present, the commercial products derived from this plant are merchandised extensively and used worldwide. Recently, systematic and continuous studies evaluated the colchicine-like activity of a common decorative plant found widely in tropical countries, Dong Deung (Gl. superba, Family Liliaceae) [55], which highlighted the benefits of this plant used for metaphase chromosome preparation in mosquitoes [14, 24, 56-58]. Various concentrations and/or extracted-fractions of dried Gl. superba seed and rhizome powders yielded similar metaphase rates and an average number of metaphase chromosomes per positive mosquito to synthetic colchicine solution, indicating that these extracts could be used to replace colchicine. In addition, the authors also mentioned that considerable budget savings could be realized by using their techniques.

Other benefits include a decorative plant that can be bought at many shops in Thailand's flower-markets, and it is hoped elsewhere in tropical countries. It can be grown easily in smallspaced land and outdoors with general fertilizers (e.g., simple formula chemical fertilizer, organic fertilizer and animal manure), which are necessary to promote its growth. It takes about 5-7 months to grow from small budding-rhizomes into mature tree with flowers and green pods (Figure $7 \mathrm{a}-\mathrm{d}$ ). 


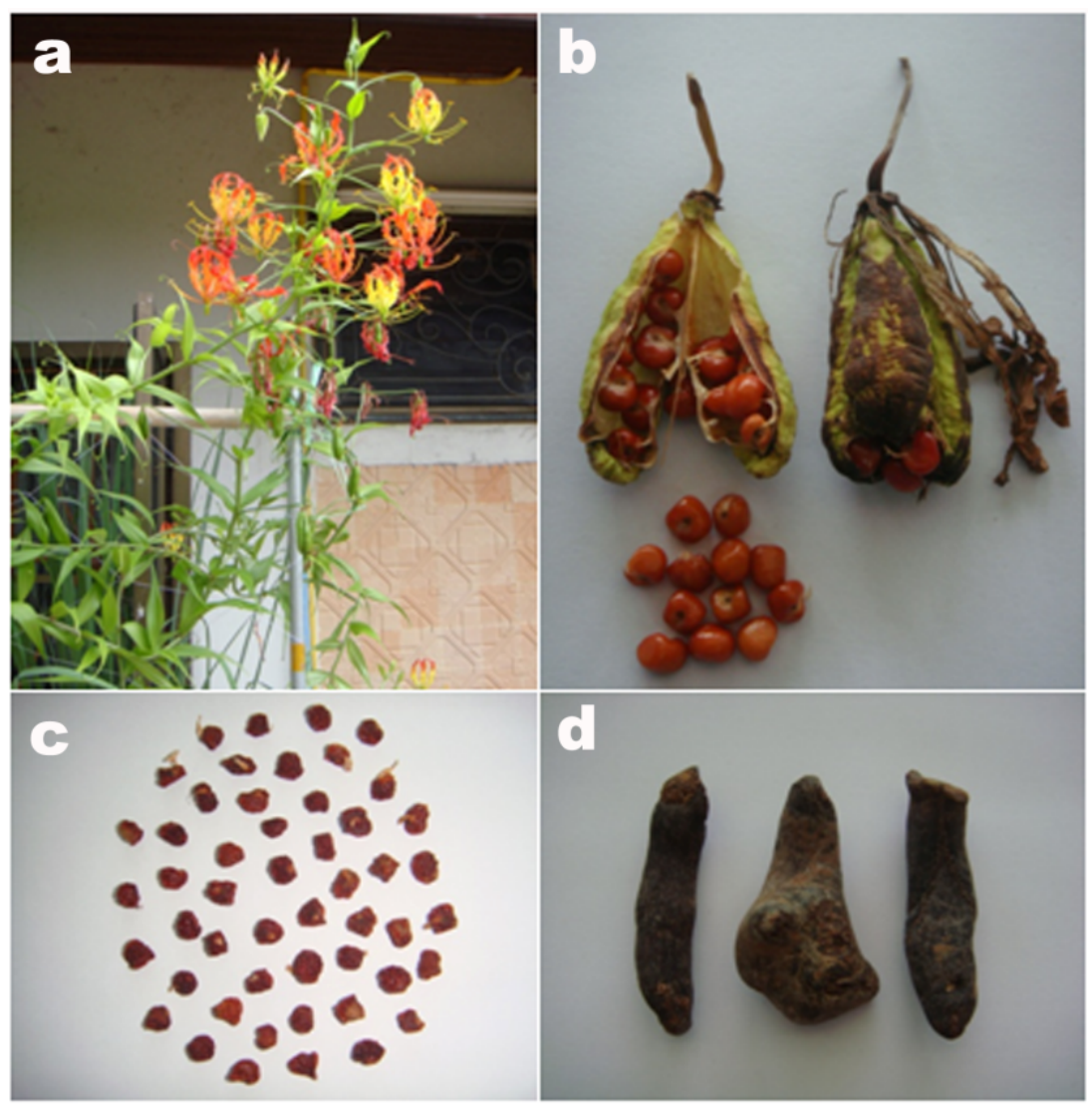

Figure 7. Showing a common decorative plant, Dong Deung (Gl. superba). (a) Dong Deung trees with beautiful flowers and green pods, (b) Ripe and broken Dong Deung pods with reddish-orange seeds, (c) Dried Dong Deung seeds and (d) Dried Dong Deung rhizomes

5.2.2. Preparation of the metaphase chromosomes from adult females and males and fourth instar larvae

\subsubsection{Procedures}

Metaphase chromosomes for adult females and males were prepared using the modified techniques described by [25]. The newly emerged adult females and males aged up to about 6-12 hours were starved, anaesthetized with ether and placed on their side on a slide under a binocular microscope. A needle was made by drawing out a glass capillary tube in a flame until the pointed end was approximately $80-100 \mu \mathrm{m}$ in diameter; the shorter the needle the easier it was to handle. An inoculation was made into the post-spiracular area of the mesothorax, and a filtrate of $0.5 \%$ solution of dried Gl. superba seed powder was introduced into each mosquito by gently blowing down the attached rubber tube. The volume of inoculums 
could be controlled by observing the extension of abdomen until it was similar in size to the fully-engorged mosquitoes post fed on $10 \%$ sucrose solution. A few minutes after inoculation, most of the mosquitoes had recovered completely. Five inoculated mosquitoes were then kept in a $10-\mathrm{ml}$ test tube $(1.5 \mathrm{~cm}$ in diameter and $10 \mathrm{~cm}$ in length), with cotton wool soaked by 3 drops of distilled water closing the opened-side in order to provide adequate moisture. Then, the cotton wool was sealed with paraffin and the test tube held in an insectarium at $27 \pm 2{ }^{\circ} \mathrm{C}$ and $70-80 \%$ relative humidity for 3 hours (Figure $8 \mathrm{a}-\mathrm{c}$ ).

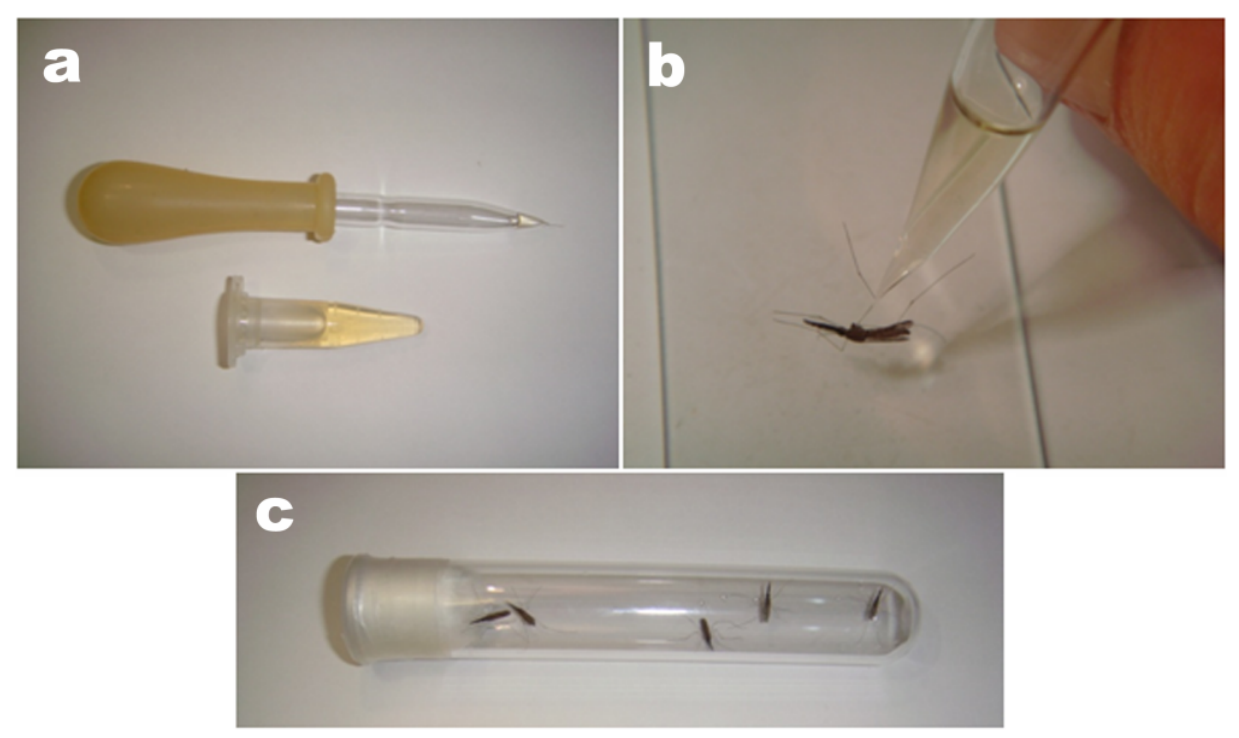

Figure 8. (a) Lower row: $1 \mathrm{ml}$ filtrate of $0.5 \%$ solution of dried Gl. superba seed powder filled in a 1.5-ml microcentrifuge tube, and upper row: an inoculation glass-needle filled with a filtrate. (b) Intra-thoracic inoculation of a filtrate into the post-spiracular area of the mesothorax. (c) Five inoculated mosquitoes kept in a 10-ml test tube

The inoculated mosquitoes were dissected in a small drop of $1 \%$ hypotonic sodium citrate solution on a siliconized slide by pulling out the last abdominal segment to obtain the ovaries or testes under a binocular microscope. The organs obtained were left in $1 \%$ hypotonic sodium citrate solution for 10 minutes, and then transferred to a small drop of Carnoy's fixative on a siliconized slide for at least 2 minutes. Then, a drop of $60 \%$ acetic acid was added, and the organs were torn and mixed well with dissecting needles. A drop of cell suspension was placed on a clean microscopic slide on a warming plate at about $45-50^{\circ} \mathrm{C}$. Droplets of cells were released slowly from a Pasteur pipette to form a circular trail of monolayer cells. The dried slides were stained with $20 \%$ Giemsa in phosphate buffer $\mathrm{pH} 7.2$ for 1 hour, rinsed with deionized water, air-dried at room temperature, mounted in Permount ${ }^{\circledR}$ (Fisher, Fairlawn, NJ, USA) and examined under a green filter compound microscope. Metaphase karyotypes were identified by following the standard descriptions (Figure 9) [59-60]. 


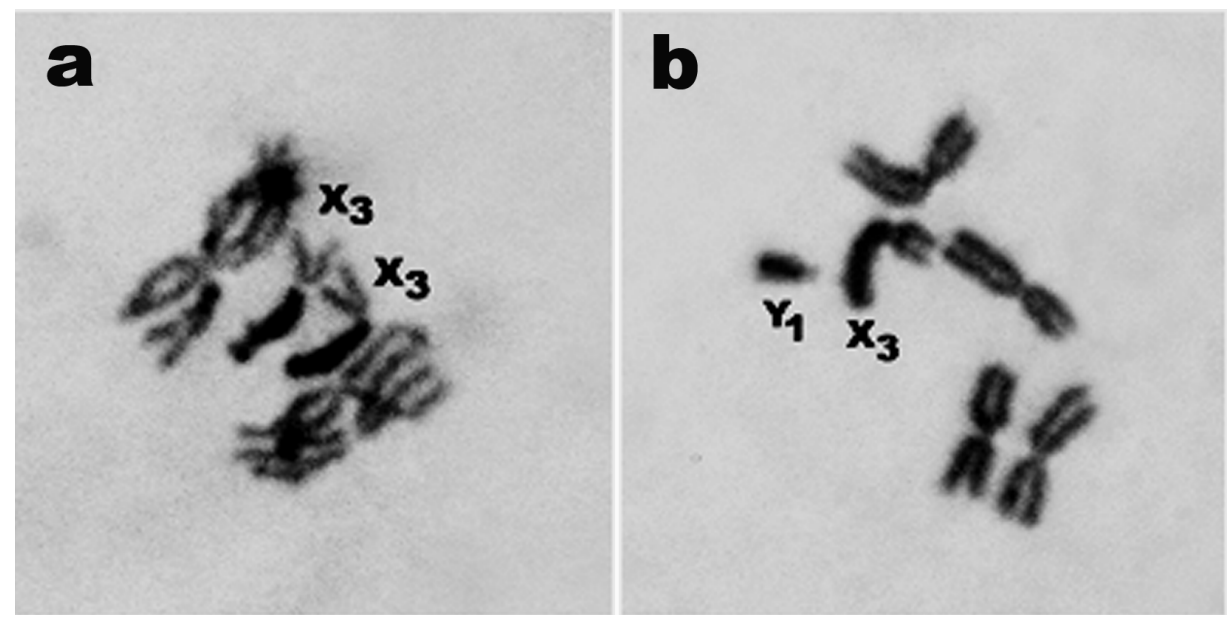

Figure 9. Metaphase chromosomes of An. paraliae Form A. (a) Ovary chromosomes, showing homozygous large submetacentric $X_{3}$ chromosomes. (b) Testis chromosomes, showing large submetacentric $X_{3}$ and small telocentric $Y_{1}$ chromosomes

The techniques for metaphase chromosome preparations in fourth instar larvae mainly followed those described above, except for the 5 fourth instar larvae that were incubated with a $1 \mathrm{ml}$ filtrate of $0.5 \%$ dried Gl. superba seed powder solution in a $10-\mathrm{ml}$ test tube for two hours. Then, the larval brains were excised, fixed, smeared, stained with Giemsa, mounted and examined under a green filter compound microscope (Figure 10).
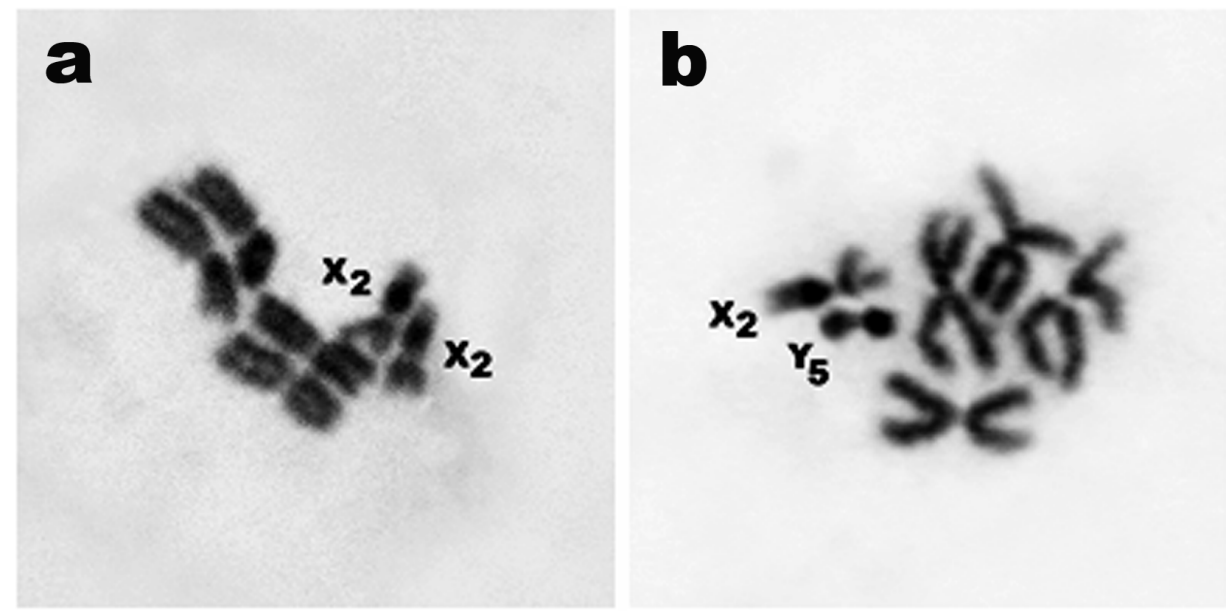

Figure 10. Metaphase chromosomes from brains of An. campestris-like Form E. (a) Showing homozygous submetacentric $X_{2}$ chromosomes. (b) Showing submetacentric $X_{2}$ and small metacentric $Y_{5}$ chromosomes 


\subsection{Preparation of the polytene chromosome from larval salivary glands}

\subsubsection{Procedures}

Salivary gland polytene chromosomes were prepared using the slightly modified published techniques [26, 61]. The early fourth instar larvae were removed from the rearing tray by a dropper and rinsed in clean distilled water. A healthy larva with flared-thorax in appearance was picked up with forceps, attached to filter paper to remove excess water, placed on a siliconized slide filled with a drop of $1 \%$ hypotonic sodium citrate solution, and then dissected under a binocular microscope. The head was cut off, and one dissecting needle was inserted through the anterior end of thorax to posterior end. Then, another dissecting needle was scratched along the line of the inserted needle to tear the thorax integument, open the thorax and take out the internal organs before the thorax and abdomen were transferred into a drop of $15 \%$ acetic acid on a siliconized slide. The bilobed salivary glands were removed from the thorax using dissecting needles, and only the whitish anterior lobe of each salivary gland was transferred into a small drop of $45 \%$ acetic acid on a siliconized slide and left for 1 minute. After that, one drop of $2 \%$ aceto-lactic orcein stain was added. After 15 minutes of staining, a grease-free $22 \mathrm{~mm}^{2}$ coverslip was placed on the stained salivary glands. The preparation was wrapped firmly in filter paper and gently pressed with a thumb to squash and spread the chromosomes. Then, the coverslip edges were sealed with transparent nail varnish. The prepared chromosomes were scrutinized under a green filter compound microscope. The arm of the polytene chromosomes was identified by following the standard map (Figure 11) [61].
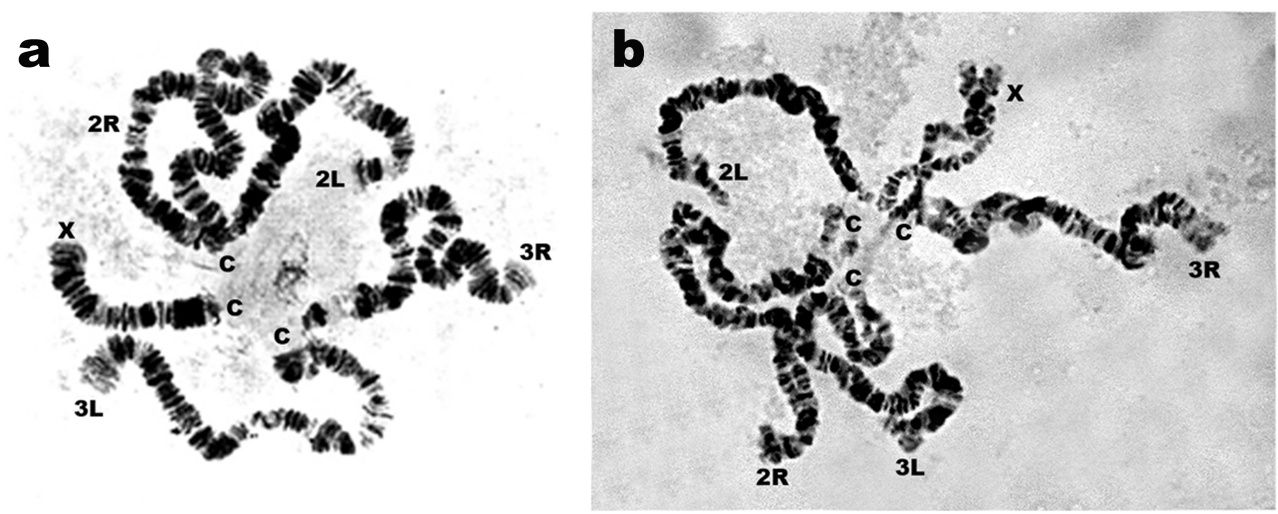

Figure 11. (a) Complete synaptic salivary gland polytene chromosome of An.campestris-like Form E. (b) Homosequential asynapsis in all autosomes and the X chromosome from crosses between An.campestris-like Form E and An. barbirostris species A1

Notes: by application of this robust systematic procedure, 5 sibling species members have recently been recognized in the taxon An. barbirostris complex within 2 years [14-16]. In addition, 8 species comprising a total of 26 subspecies (cytological forms) have been recognized during the past decade, i.e., An. vagus Forms A and B [62], An. pullus Forms A and B (= An. 
yatsushiroensis) [62], An. sinensis Forms A and B [64-66], An. aconitus Forms B and C [67], An. barbirostris species A1 (Forms A, B, C and D) and A2 (Forms A and B) [14-16], An. campestrislike Forms B, E, and F [68], An. peditaeniatus Forms B, C, D, E [69], and An. paraliae Forms A, B, $\mathrm{C}, \mathrm{D}$ and $\mathrm{E}$ [unpublished data].

\section{Conclusion}

The formation of robust systematic procedures is highly anticipated, based on the crossing experiments between iso-female lines using cytological markers (characteristics of metaphase chromosomes/karyotypic forms). Together with this information, the data on comparative sequence analyses of some specific genomic regions (rDNA and mtDNA) would bring success in recognizing and reliably identifying sibling species and/or subspecies members within the taxon of other Anopheles species complexes. In addition, the detailed techniques necessary for the establishment of difficult-to-rear anopheline species, which yield high rates of attractive metaphase and polytene chromosomes and potent adults for crossing experiments, would be main keys leading to successful study on the population-genetic structure of Anopheles vectors. These factors are important for studying the biology, behavior of Anopheles species, as well as for an epidemiology and a control approach of the targeted vector species.

\section{Acknowledgements}

Sincere thanks are extended to the Thailand Research Fund (TRF Advanced Research Scholar: BRG/14/2545 and BRG5380021, and TRF Senior Research Scholar: RTA5480006), the Thailand Research Fund through the Royal Golden Jubilee Ph.D. Program (Grant No. PHD/0044/2546, PHD/0052/2548, PHD/0082/2549, PHD/0031/2550, PHD/0297/2551 and PHD/0356/2552), Biodiversity Research and Training Program (Grant No. BRT R_249004, 250009 and 252005: 2006-2009), and Faculty of Medicine Research Fund, Chiang Mai University, Chiang Mai, Thailand, for their continuous financial support in the population-genetic study of Anopheles vectors in Thailand.

\section{Author details}

Wej Choochote* and Atiporn Saeung

*Address all correspondence to: wchoocho@mail.med.cmu.ac.th

Department of Parasitology, Faculty of Medicine, Chiang Mai University, Chiang Mai, Thailand 


\section{References}

[1] Foley DH, Beebe N, Torres E, Saul A (1996) Misidentification of a Philippine malaria vector revealed by allozyme and ribosomal DNA markers Am. J. Trop. Med. Hyg. 54: 46-48.

[2] Van Bortel W, Harbach RE, Trung HD, Roelants P, Backeljau T, Coosemans M (2001) Confirmation of Anopheles varuna in vietnam, previously misidentified and mistargeted as the malaria vector Anopheles minimus. Am. J. Trop. Med. Hyg. 65: 729-732.

[3] World Health Organization (2007) Anopheline species complexes in South and South-East Asia. SEARO Technical Publication No. 57. WHO Regional Office for South-East Asia, New Delhi. 102 p.

[4] Singh OP, Nanda N, Dev V, Bali P, Sohail M, Mehrunnisa A, Adak T, Dash AP (2010) Molecular evidence of misidentification of Anopheles minimus as Anopheles fluviatilis in Assam (India). Acta Trop. 113: 241-244.

[5] Harbach RE (2012) Genus Anopheles Meigen, 1818. Available: http://mosquito-taxonomic-inventory.info/genus-anopheles-meigen-1818. Accessed 2012 May 14.

[6] Kanda T, Takai K, Chiang GL, Cheong WH, Sucharit S (1981) Hybridization and some biological facts of seven strains of the Anopheles leucosphyrus group (Reid, 1968). Jap. J. Sanit. Zool. 32: 321-329.

[7] Baimai V, Andre RG, Harrison BA, Kijchalao U, Panthusiri L (1987) Crossing and chromosomal evidence for two additional sibling species within the taxon Anopheles dirus Peyton and Harrison (Diptera: Culicidae) in Thailand. Proc. Entomol. Soc. Wash. 89: 157-166.

[8] Baimai V, Poopittayasataporn A, Kijchalao U (1988) Cytological differences and chromosomal rearrangements in four members of the Anopheles dirus complex (Diptera: Culicidae) in Thailand. Genome 30: 372-379.

[9] Sawadipanich Y, Baimai V, Harrison BA (1990) Anopheles dirus species E: Chromosomal and crossing evidence for another member of the Dirus complex. J. Am. Mosq. Control Assoc. 6: 477-481.

[10] Subbarao SK (1998) Anopheline species complexes in South-East Asia. WHO. Tech. Publ. SEARO. 18: 1-82.

[11] Peterson HE (1980) A comment on "mate recognition systems". Evolution 34: 330-331.

[12] Green CA, Rattanarithikul R, Charoensub A (1992) Population genetic confirmation of species status of the malaria vectors Anopheles willmori and An. pseudowillmori in Thailand and chromosome phylogeny of the Maculatus group of mosquitoes. Med. Vet. Entomol. 6: 335-341. 
[13] Coluzzi M (1970) Sibling species in Anopheles and their importance to malariology. Misc. Publ. Ent. Soc. Am. 7: 63-77.

[14] Saeung A, Otsuka Y, Baimai V, Somboon P, Pitasawat B, Tuetun B, Junkum A, Takaoka H, Choochote W (2007) Cytogenetic and molecular evidence for two species in the Anopheles barbirostris complex (Diptera: Culicidae) in Thailand. Parasitol. Res. 101: 1337-1344.

[15] Saeung A, Baimai V, Otsuka Y, Rattanarithikul R, Somboon P, Junkum A, Tuetun B, Takaoka H, Choochote W (2008) Molecular and cytogenetic evidence of three sibling species of the Anopheles barbirostris Form A (Diptera: Culicidae) in Thailand. Parasitol. Res. 102: 499-507.

[16] Suwannamit S, Baimai V, Otsuka Y, Saeung A, Thongsahuan S, Tuetun B, Apiwathnasorn C, Jariyapan N, Somboon P, Takaoka H, Choochote W (2009) Cytogenetic and molecular evidence for an additional new species within the taxon Anopheles barbirostris (Diptera: Culicidae) in Thailand. Parasitol. Res. 104: 905-918.

[17] Saeung A (2012) Anopheles (Diptera: Culicidae) species complex in Thailand: Identification, distribution, bionomics and malaria-vector importance. Int. J. Parasitol. Res. 4: 75-82.

[18] Green, CA, Gass RF, Munstermann LE, Baimai V (1990) Population-genetic evidence for two species in Anopheles minimus in Thailand. Med. Vet. Entomol. 4: 25-34.

[19] Collins FH, Paskewitz SM (1996) A review of the use of ribosomal DNA (rDNA) to differentiate among cryptic Anopheles species. Insect Mol. Biol. 5: 1-9.

[20] Harbach RE (2004) The classification of genus Anopheles (Diptera: Culicidae): a working hypothesis of phylogenetic relationships. Bull. Entomol. Res. 94: 537-553.

[21] Garros C, Harbach RE, Manguin S (2005) Morphological assessment and molecular phylogenetics of the Funestus and Minimus Groups of Anopheles (Cellia). J. Med. Entomol. 42: 522-536.

[22] Chen B, Butlin RK, Pedro PM, Wang XZ, Harbach RE (2006) Molecular variation, systematics and distribution of the Anopheles fluviatilis complex in southern Asia. Med. Vet. Entomol. 20: 33-43.

[23] Singh OP, Chandra D, Nanda N, Sharma SK, Htun PT, Adak T, Subbarao SK, Dash AP (2006) On the conspecificity of Anopheles fluviatilis species S with Anopheles minimus species C. J. Biosci. 31: 671-677.

[24] Saeung A (2010) Genetic study of Anopheles barbirostris. Ph.D. Thesis, Chiang Mai University. $110 \mathrm{p}$.

[25] Choochote W, Rongsriyam Y, Tookyang B, Pakdicharoen A, Likitvong K (1992) A technique for chromosome preparation in adult mosquitoes. Mosq-Borne Dis. Bull. 9: 20-22. 
[26] Kanda T (1979) Improved techniques for the preparation of polytene chromosomes for some Anopheles mosquitoes. Mosq. News 39: 568-574.

[27] Mourya DT, Ilkal MA, Mishra AC, Jacob PG, Pant U, Ramanujam S, Mavale MS, Bhat HR, Dhanda V (1989) Isolation of Japanese encephalitis virus from mosquitoes collected in Karnataka state, India during 1985 to 1987.Trans. R. Soc. Trop. Med. Hyg. 83: 550-552.

[28] George S, George JP, Rao JA (1987) Isolation of Japanese encephalitis and West Nile viruses from mosquitoes collected in Kolar district of Karnataka state during 1977-79. Indian J. Med. Res. 85: 235-238.

[29] Thenmozhi V, Rajendran R, Ayanar K, Manavalan R, Tyagi BK (2006) Long-term study of Japanese encephalitis virus infection in Anopheles subpictus in Cuddalore district, Tamil Nadu, South India. Trop. Med. Int. Hlth. 11: 288-293.

[30] Chakravarty SK, Sarkar JK, Chakravarty MS, Mukherjee MK, Mukherjee KK, Das BC, Hati AK (1975) The first epidemic of Japanese encephalitis studied in India-virological studies. Indian J. Med. Res. 63: 77-82.

[31] Choochote W, Sucharit S, Abeyewickreme W (1983) A note on adaptation of Anopheles annularis Van Der Wulp, Kanchanaburi, Thailand to free mating in a $30 \times 30 \times 30$ cm cage. Southeast Asian J. Trop. Med. Public Health, 14: 559-560.

[32] Choochote W, Sucharit S, Khamboonruang C, Somboon P, Maleewong W, Suwapanit P (1985) Adaptation of various species and strains of Anopheles mosquitoes to natural copulation in a $30 \mathrm{~cm}$ cube cage. J. Parasit. Trop. Med. Ass. Thailand 8: 44-47.

[33] Baker RH, French WL, Kitzmiller JB (1962) Induced copulation in Anopheles mosquitoes. Mosq. News 22: 16-17.

[34] Ow Yang CK, Sta Maria FL, Wharton RH (1963) Maintenance of a laboratory colony of Anopheles maculatus by artificial mating. Mosq. News 23: 34-35.

[35] Chomcharn Y (1979) The study of Plasmodium falciparum in Thailand with respect to the mosquito vector, Anopheles balabacensis baisas and the effect of primaquine on the gametocytes and sporogony. Ph.D. Thesis, Mahidol University. pp. 46-48.

[36] Gerberg EJ, Barnard DR, Ward RA (1994) Procedures for laboratory rearing of specific mosquitoes, In: Manual for mosquito rearing and experimental techniques. Louisiana: Allen Press. pp. 41-45.

[37] Bangs MJ, Soelarto T, Barodji, Wicaksana BP, Boewono DT (2002) Colonization of Anopheles maculatus from Central Java, Indonesia. J. Am. Mosq. Control Assoc. 18: 359-363.

[38] Kim SJ, Choochote W, Jitpakdi A, Junkum A, Park SJ, Min GS (2003) Establishment of a self-mating mosquito colony of Anopheles sinensis from Korea. Korean J. Entomol. 33: 267-271. 
[39] Da Silva AN, Dos Santos CC, Lacerda RN, Santa Rosa EP, De Souza RT, Galiza D, Sucupira I, Conn JE, Póvoa MM (2006) Laboratory colonization of Anopheles aquasalis (Diptera: Culicidae) in Belém, Pará, Brazil. J. Med. Entomol. 43: 107-119.

[40] Clements AN (1999) The biology of mosquitoes. Vol. 2. Sensory reception and behavior. Oxon, UK: CABI Publishing.

[41] Reid JA (1968) Anopheline mosquitoes of Malaya and Borneo. Stud. Inst. Med. Res. Malaya 31: 1-520.

[42] Harrison BA, Scanlon JE (1975) Medical entomology studies-II. The subgenus Anopheles in Thailand (Diptera: Culicidae). Contrib. Am. Entomol. Inst. 12: 1-307.

[43] Yuh YS, Liu JY, Shaio MF (1997) Chromosome number of Trichomonas vaginalis. J. Parasitol. 83: 551-553.

[44] Petkeviciute RA (1996) Chromosome study in the progenetic cestode Cyathocephalus truncatus (Cestoda: Spathebothriidea). Int. J. Parasitol. 26: 1211-1216.

[45] Hirai H, Toguchi I, Saitoh Y, Kawanaka M, Sugiyama H, Habe S, Okamoto M, Hirata M, Shimada M, Tiu WU, Lai K, Upatham ES, Agatsuma T (2000) Chromosomal differentiation of the Schistosoma japonicum. Int. J. Parasitol. 30: 441-452.

[46] Petkeviciute R, Staneviciute G, Kiseliene V (1995) Mitotic chromosomes of Sphaerostomum bramae (Muller, 1776) Szidat, 1944. J. Helminthol. 69: 347-349.

[47] Baker RH, Aslamkhan M (1969) Karyotypes of some Asian mosquitoes of the subfamily culicinae (Diptera: Culicidae). J. Med. Entomol. 6: 44-52.

[48] Baimai V (1977) Chromosomal polymorphisms of constitutive heterochromatin and inversions in Drosophila. Genetics 85: 85-93.

[49] Bermard J, Max K (1977) Heterochromatin variation in Cryptobothrus chrysophorus. Chromosoma 65: 59-79.

[50] Nunamarker RA, Brown SE, Knudson DL (1996) Metaphase chromosomes of Culicoides variipennis (Diptera: Ceratopogonidae). J. Med. Entomol. 35: 871-873.

[51] Vosa CG (1973) Heterochromatin recognition and analysis of chromosome variation in Scilla sibirica. Chromosoma 43: 269-278.

[52] Marks GE (1976) Variation of Giemsa banding patterns in the chromosomes of Anemone blanda. Chromosoma 5: 179-184.

[53] Insel PA (1996) Analgesic-antipyretic and anti-inflammatory agents and drugs employed in the treatment of gout. In: Hardman JG, Limbird LE, editors. The pharmacological basis of therapeutic, 9th ed. McGraw-Hill, New York. pp. 647-649.

[54] Haraguchi T, Kaneda T, Hiraoka Y (1997) Dynamics of chromosomes and microtubules visualized by multiple wavelength fluorescence imaging in living mammalian cells: effects of mitotic inhibitors on cell cycle progression. Genes. Cells 2: 369-380. 
[55] Smitinand T (1980) Thai plant names: Botanical names-ver-nacular names. Royal Forest Department, Bangkok.

[56] Jitpakdi A, Choochote W, Insun D, Tippawangkosol P, Keha P, Pitasawat B (1999) Screening of ten plant species for metaphase chromosome preparation in adult mosquitos (Diptera: Culicidae) using an inoculation technique. J. Med. Entomol. 36: 892-895.

[57] Choochote W, Pitasawat B, Jitpakdi A, Rattanachanpichai E, Riyong D, Leemingsawat S, Wongkamchai S (2001) The application of ethanol-extracted Gloriosa superba for metaphase chromosome preparation in mosquitoes. Southeast Asian J.Trop. Med. Public Health, 32: 76-82.

[58] Choochote W, Rongsriyam K, Pitasawat B, Jitpakdi A, Rattanachanpichai E, Junkum A, Tuetun B, Chaiwong P (2004) Evaluation of the colchicine-like activity of Gloriosa superba-extracted fractions for mosquito (Diptera: Culicidae) cytogenetic study. J. Med. Entomol. 41: 672-676.

[59] Baimai V, Rattanarithikul R, Kijchalao U (1993) Metaphase karyotypes of Anopheles of Thailand and Southeast Asia: I. The Hyrcanus group. J. Am. Mosq. Control Assoc. 9: 59-67.

[60] Baimai V, Rattanarithikul R, Kijchalao U (1995) Metaphase karyotypes of Anopheles of Thailand and Southeast Asia: IV, The Barbirostris and Umbrosus species groups, subgenus Anopheles (Diptera: Culicidae). J. Am. Mosq. Control Assoc. 11: 323-328.

[61] White GB, Coluzzi M, Zahar AR (1975) Review of cytogenetic studies on anopheline vectors of malaria. WHO/MAL/75, 489.35 p.

[62] Choochote W, Jitpakdi A, Sukontason K, Chaithong U, Wongkamchai S, Pitasawat B, Jariyapan N, Suntaravitun T, Rattanachanpichai E, Sukontason K, Leemingsawat S, Rongsriyam Y (2002) Intraspecific hybridization of two karyotypic forms of Anopheles vagus (Diptera: Culicidae) and the related egg surface topography. Southeast Asian J. Trop. Med. Public Health, 33 (suppl 3): 29-35.

[63] Park SJ, Choochote W, Jitpakdi A, Junkum A, Kim SJ, Jariyapan N (2003) Evidence for a conspecific relationship between two morphologically and cytologically different forms of Korean Anopheles pullus mosquito. Mol. Cells 16: 354-360.

[64] Choochote W, Jitpakdi A, Rongsriyam Y, Komalamisra N, Pitasawat B, Palakul K (1998) Isoenzyme study and hybridization of two forms of Anopheles sinensis (Diptera: Culicidae) in Northern Thailand. Southeast Asian J. Trop. Med. Public Health, 29: 841-848.

[65] Min GS, Choochote W, Jitpakdi A, Kim SJ, Kim W, Jung J, Junkum A (2002) Intraspecific hybridization of Anopheles sinensis (Diptera: Culicidae) strains from Thailand and Korea. Mol. Cells 14: 198-204. 
[66] Park MH, Choochote W, Kim SJ, Somboon P, Saeung A, Tuetan B, Tsuda Y, Takagi M, Joshi D, Ma Y, Min GS (2008) Non-reproductive isolation among four allopatric strains of Anopheles sinensis in Asia. J. Am. Mosq. Control Assoc. 24: 489-495.

[67] Junkum A, Jitpakdi A, Jariyapan N, Komalamisra N, Somboon P, Suwonkerd W, Saejeng A, Bates PA, Choochote W 2005. Evidence to support two conspecific cytological races on Anopheles aconitus in Thailand. J. Vector Ecol. 30: 213-224.

[68] Thongsahuan S, Baimai V, Otsuka Y, Saeung A, Tuetun B, Jariyapan N, Suwannamit S, Somboon P, Jitpakdi A, Takaoka H, Choochote W (2009) Karyotypic variation and geographic distribution of Anopheles campestris-like (Diptera: Culicidae) in Thailand. Mem. Inst. Oswaldo Cruz 104: 558-566.

[69] Choochote W (2011) Evidence to support karyotypic variation of the mosquito, Anopheles peditaeniatus in Thailand. J. Insect Sci. 11: 10. 
